\title{
A Fog-and-Tube Scrubber for the Removal of Diesel Particulate Matter from Engine Exhaust
}

Aerosol and Air Quality Research

\author{
Joseph Tabor ${ }^{1}$, Emily Sarver ${ }^{1 *}$, John R. Saylor ${ }^{2}$ \\ ${ }^{1}$ Department of Mining and Minerals Engineering, Virginia Tech, Blacksburg, VA 24061, USA \\ ${ }^{2}$ Department of Mechanical Engineering, Clemson University, Clemson, SC 29634, USA
}

Diesel particulate matter (DPM), the solid portion of diesel exhaust, has been linked to a range of deleterious health impacts. While a number of control strategies have been effective at reducing DPM in some environments, exposure risks are still high in others such as underground mines. In prior work, a novel scrubber treatment that used fog to remove DPM from engine exhaust was successfully prototyped in bench-scale laboratory experiments. Here, for the first time, the treatment concept was scaled up and field tested in a stone mine. An exhaust blower was used to pull fog, diesel exhaust, and mine air through a 30.5-meter long tube, enabling coagulation of DPM and fog drops resulting in their subsequent removal. Excluding one of the eleven tests, which appeared to be an outlier, the results showed that this fog-and-tube scrubber removed an average of $63 \%$ of particles (11.5-154 nm) as compared to $18 \%$ in the control case (without fog), yielding an average improvement of $45 \%$. Computer simulations suggest that the observed particle removal is predominantly due to rapid thermal coagulation between the DPM and fog drops, followed by removal of the DPM-laden drops via inertial impaction with the tube walls.

Keywords: Diesel particulate, Ultrafine aerosol, Exhaust treatment, Occupational health

\section{INTRODUCTION}

Diesel particulate matter (DPM) is the solid fraction of diesel exhaust. It consists primarily of carbonaceous solids and heavy hydrocarbons, and can also contain ash, silicates, sulfates, and metallic abrasion particles (Kittelson, 1998). DPM particles are found primarily in the nanometer size range (Kittleson, 1998), and can penetrate deep into the alveolar region of the lung (Heyder, et al., 1987). Chronic exposures have been linked to a range of respiratory and cardiovascular ailments (Sydbom et al., 2001; Cantrell and Watts, 1997; Wade and Newman, 1993). Due to the use of heavy diesel equipment in confined spaces, underground mines are known to have some of the highest DPM exposure risks (Bugarski et al., 2011). Mine operators use a range of engineering controls to limit DPM exposures including exhaust aftertreatments, such as the use of diesel particulate filters (DPFs), alternative fuels such as biodiesel, engine controls, diesel oxidation catalytic converters, and enhanced ventilation. Each of these technologies has certain drawbacks. For example, enhanced ventilation can be an expensive approach to reducing DPM levels, engine controls tend to result in reduced horsepower (Schnakenberg and Bugarski, 2002), and DPFs require a regeneration process (Bugarkski et al., 2011).

Another important issue is that the DPM reductions obtained from all of the common control methods tend to be quantified on a mass basis, while there is growing evidence that the deleterious health effects caused by nanoscale particles is proportional to their number, or perhaps their surface area, not their mass (Ristovski et al., 2012; Pope et al., 1995; Dockery et al., 1993; Oberdorster et al., 2005, 2007). It may be the case that many of the measured DPM reductions by these technologies are in the larger end of the size range and that the finer, more hazardous particles are not significantly affected. Indeed, Dementhon and Martin (1997) showed that small DPM particles were actually created during the regeneration process in DPFs. Vaarashlahti et al. (2004) 
showed that at high engine loads, a diesel engine operating with a continuously regenerating DPF increased the number density of particles in the $10 \mathrm{~nm}$ diameter range by over two orders of magnitude. Similar increases were observed with the use of 5 DPFs by other researchers (Maricq et al., 2002; Vogt et al., 2003; Kittelson et al., 2009; Bugarski et al., 2009). DPM exposures remain high in some mines (e.g., see compliance monitoring data collected by the US Mine Safety and Health Administration, MSHA, 2021). Clearly, additional methods are needed for DPM reduction, particularly approaches that will reduce particle loading across the entire range of particle diameters.

To address this problem, Rojas-Mendoza et al. $(2015,2017 \mathrm{a}, \mathrm{b})$ presented and bench tested a novel scrubber concept that used a high density of micron-scale water droplets (hereinafter referred to as fog) to remove DPM from an exhaust stream. Laboratory results using a diluted bleed-off from the exhaust of a small engine showed significant particle removal using the fog treatment versus a control case (Rojas-Mendoza et al., 2017a, b). On average, nearly $90 \%$ of particles (10-420 nm) were removed with the fog compared to $46 \%$ without it, which represents an improvement due to the fog of about 44\% (Rojas-Mendoza et al., 2017a). On the basis of mass, about $58 \%$ of the DPM was removed with the treatment compared to just $12 \%$ without, which represents an improvement of about 46\% (Rojas-Mendoza et al., 2017b). It was proposed that DPM removal occurs via a two-step process, whereby the DPM quickly coagulates with the fog drops, which then settle in the laboratory scrubber apparatus by gravity.

In the current study, the fogging scrubber concept was scaled up and field tested in an underground stone mine to gather data under more practical conditions. Herein the results of these field tests are presented along with computational simulations used to gain further insights into the mechanisms influencing the DPM removal.

\section{EXPERIMENTAL}

\subsection{Site Details}

The primary goal of the field testing was to determine the degree to which a fog-and-tube scrubber could remove DPM directly from vehicle exhaust. Removal of background levels of DPM from the mine air was not a goal. However, to ensure that temperatures and relative humidities characteristic of a mining environment were considered, experiments were conducted in a mine. Since exhaust pipes are generally the source point of all DPM in mines, successful demonstration of DPM removal at a point source presents a potential path forward to removing or reducing DPM in mines without treating the entire mine air volume.

The specific testing location was in a large tunnel (approximately $12 \mathrm{~m} \times 12 \mathrm{~m}$ ), at a depth of approximately $185 \mathrm{~m}$ in a stone mine. The tunnel is within the primary intake airway for the mine (i.e., where clean air enters the mine) and has only intermittent traffic from passenger vehicles; it is not influenced by emissions from mining equipment. Thus, this location is characterized by relatively low and consistent background particle concentrations in the nanometer size range. The depth of the testing location also ensured that the temperature $\left(\sim 15^{\circ} \mathrm{C}\right)$ and relative humidity of the air ( $95 \%)$ were relatively constant during the testing periods.

\subsection{Apparatus}

A schematic of the scrubber apparatus is presented in Fig. 1. Over the course of 11 separate field tests, five diesel vehicles ranging from a small 4-passenger buggy to a full-size school bus were used as the DPM source (see Table S1 in the Supplemental Information, SI). In all tests, the vehicles were stationary, and the exhaust was obtained by placing one end of a $7.3 \mathrm{~m}$ section of $35.6 \mathrm{~cm}$ diameter, ribbed, flexible Mylar tubing over the tailpipe. This relatively long section of inlet tubing was used to promote mixing of the exhaust with the entrained air prior to particle measurement on the upstream (inlet) side of the fog treatment. This ensured that the relevant inlet characteristic was the averaged number density of particles and that variations in mixedness of exhaust and mine air was not a confounding factor.

Fog was generated using an MHB12 Multi-function Ultrasonic Humidifier (Mainlandmart, Ocean Mist, CA), which is referred to as the "fogger" hereinafter. On the downstream side of the fogger was a $30.5 \mathrm{~m}$ section of the same Mylar tubing, referred to as the "settling tube". At the 




Fig. 1. Fog-and-tube scrubber apparatus setup in the underground mine.

outlet of the settling tube, particles were again measured before the air exited the apparatus through a small exhaust blower.

\subsection{Particle and Fog Measurements}

Particle concentrations $\left(C_{p}, \mathrm{~cm}^{-3}\right)$ were measured just upstream of the fogger (inlet) and at the exit of the settling tube (outlet) using a pair of TSI 3910 SPMS NanoScan instruments (TSI, Shoreview, MN). The instruments sampled at a flow rate of $1 \mathrm{~L} \mathrm{~min}^{-1}$ and obtained measurements every minute. The sampling flow rate was negligible in comparison to the overall flowrate of the system (i.e., 3,000 L min ${ }^{-1}$ or $50,000 \mathrm{~cm}^{3} \mathrm{~s}^{-1}$, see below). Data was recorded in size bins between 11.5 and $410 \mathrm{~nm}$; only the 10 bins from 11.5 to $154 \mathrm{~nm}$ were used for this study since very few particles were observed in the larger bins, and measurements in those bins were similar to background particle concentrations. This size range covers the nuclei mode of the DPM particle size distribution $\left(d_{p}<50 \mathrm{~nm}\right.$ ) where the largest number of DPM particles reside, and part of the accumulation mode $\left(50 \mathrm{~nm}<\mathrm{d}_{\mathrm{p}}<1000 \mathrm{~nm}\right.$ ) (Kittelson, 1998). A diffusion dryer (DD Model 250; ATI, Owings Mills, MD) was used at the inlet of each NanoScan to remove moisture from the sample stream, thereby ensuring that fog drops were not counted as particles. The diffusion dryers also ensured that DPM removal results were conservative in the sense that DPM particles contained in a drop that hadn't been removed are counted by the outlet NanoScan, even though in the very humid environment of an underground mine, the likelihood is small that such a dropcontained DPM particle would ever dry out and present a threat to the alveolar region of a miner.

The average flow rate through the scrubber apparatus was $50,000 \mathrm{~cm}^{3} \mathrm{~S}^{-1}$, yielding a residence time from inlet NanoScan to outlet NanoScan of 60.5 seconds. The airflow was considered turbulent based on its Reynolds number $\operatorname{Re}=12,100$, where $\operatorname{Re}$ is defined as:

$\operatorname{Re}=\frac{\rho_{a} V d_{t}}{\mu a}$

where $\rho_{a}$ is the air density $\left(1.225 \mathrm{~kg} \mathrm{~m}^{-3}\right), V$ is the average air velocity through the tube $\left(0.504 \mathrm{~m} \mathrm{~s}^{-1}\right), d_{t}$ is tube diameter $(0.356 \mathrm{~m})$, and $\mu_{a}$ is the viscosity of air $\left(1.81 \times 10^{-5} \mathrm{~kg} \mathrm{~m}^{-1} \mathrm{~s}^{-1}\right)$.

Fog drop measurements were not possible in the field, however, a TSI 3330 Optical Particle Sizer (TSI, Shoreview, MN) was used in the laboratory to determine the drop size distribution generated by the fogger (see Fig. S1 in SI). Those results indicated an average drop diameter $\bar{d}_{d}=$ $4.8 \mu \mathrm{m}$, which is in good agreement with the $5 \mu \mathrm{m}$ diameter quoted by the manufacturer.

Before and after each test, the inlet and outlet NanoScans were compared by connecting the sampling inlets via a Y-tube so that they sampled the same air stream for a minimum of 15 minutes. This was done in both a low and a high DPM environment to confirm agreement between the two NanoScans for a range of concentrations. For each comparison period, the average particle 
concentration (11.5-154 nm) was computed for both instruments, and then a total scaling factor (S) was computed:

$S=\frac{\text { inlet } C_{p}}{\text { outlet } C_{p}}$

This ratio was used to correct the outlet NanoScan data from each test; across all 11 tests, $S$ ranged from 0.93 to 1.03 , with an average of 1.00 (Table S1).

For all tests, the inlet fog drop concentration $\left(C_{d}, \mathrm{~cm}^{-3}\right)$ was computed as:

$C_{d}=\frac{3 q}{4 Q \pi\left(\frac{\bar{d}_{d}}{2}\right)^{3}}$

where $q$ is the rate of water consumption $\left(\mathrm{cm}^{3} \mathrm{~s}^{-1}\right)$ by the fogger, $Q$ is the flowrate inside the settling tube $\left(50,000 \mathrm{~cm}^{3} \mathrm{~s}^{-1}\right)$, and $\bar{d}_{d}$ is the average diameter of a single droplet $(4.8 \mu \mathrm{m}$ per above). For the 11 field tests conducted for this study, $C_{d}$ varied from $1.84 \times 10^{5} \mathrm{~cm}^{-3}$ to $3.68 \times$ $10^{5} \mathrm{~cm}^{-3}$ (Table S1).

\section{RESULTS}

Fig. 2 shows the time traces of total particle concentration $(11.5-154 \mathrm{~nm})$ measured at the scrubber inlet and outlet during Test 1 for both the treatment (fog on) and control (fog off) conditions. Average inlet and outlet particle concentrations for all 11 field tests are given in Table S1. Results demonstrate that the fog-and-tube scrubber consistently and significantly reduced the inlet particle concentration. The only exception was for Test 9 , which yielded very similar results between the control and treatment conditions for all size bins. It is suspected that the fogger malfunctioned during this test, and accordingly its results are not considered hereinafter.

A total particle removal efficiency, $E$, was determined for each test:
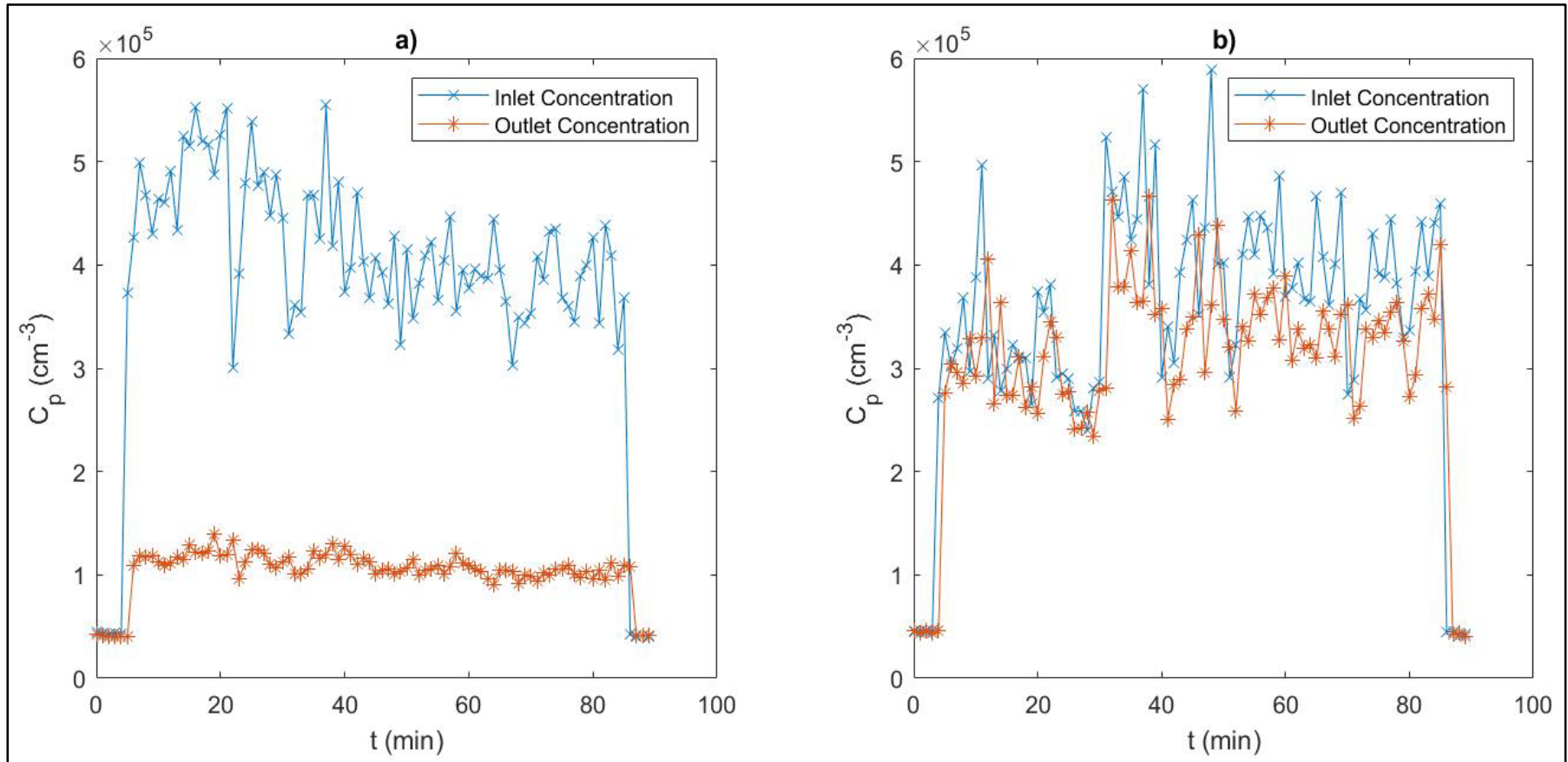

Fig. 2. Time traces of total particle concentration (11.5-154 nm) measured during Test 1 at the inlet and outlet of the fog-andtube scrubber for (a) the fog on and (b) fog off conditions. 
$E=\left(\frac{\text { inlet } C_{p}-\text { outlet } C_{p}}{\text { inlet } C_{p}}\right) \times 100 \%$

Values for $E$ ranged from $49 \%$ to $79 \%$ (average of $63 \%$ ) with the fog treatment, compared to $7 \%$ to $34 \%$ (average of $18 \%$ ) without fog (Fig. 3). This represents an average overall improvement in $E$ of $45 \%$ due to the fog treatment.

Values for $E$ were also computed for each size bin. Fig. 4 shows the results averaged across all field tests, and Table S2 shows results for each individual test. Even without fog, the tube effectively removes significant numbers of particles in the smaller bins, specifically the $11.5 \mathrm{~nm}$ and $15.4 \mathrm{~nm}$ bins. This is likely due to particle-particle coagulation (e.g., $11.5 \mathrm{~nm}$ particles combining with larger

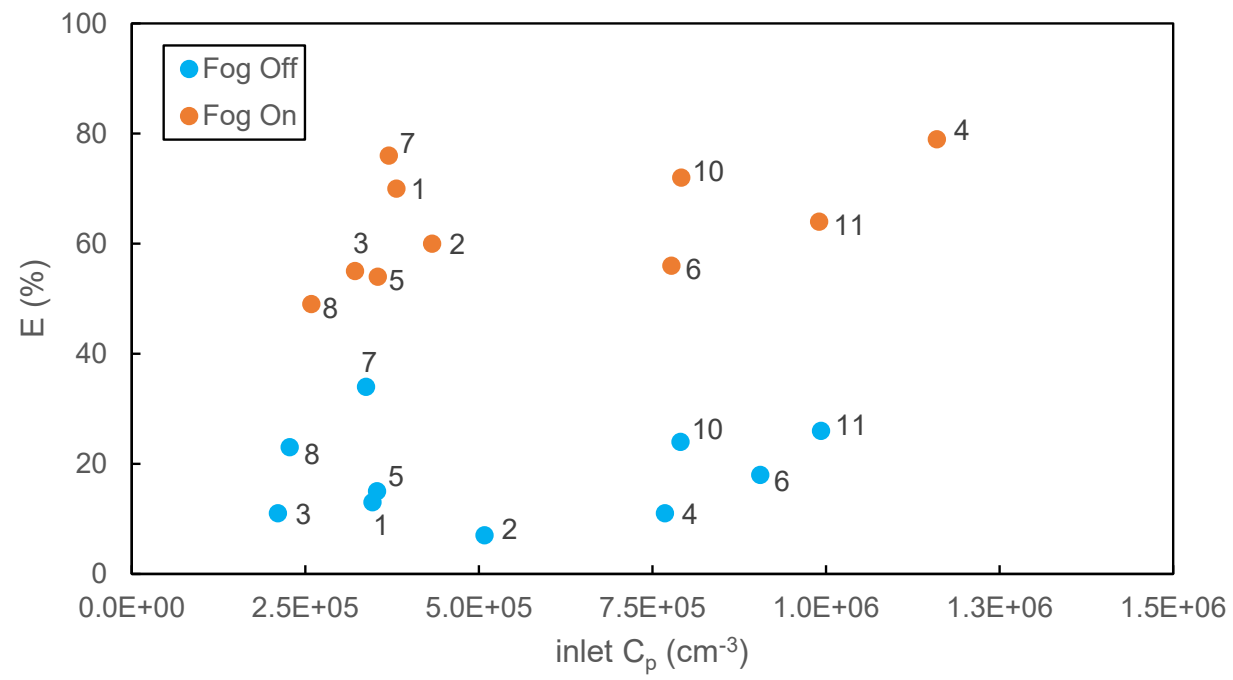

Fig. 3. Total $E$ measured for field tests of the fog-and-tube scrubber as a function of inlet particle concentration (11.5-154 nm). Data labels indicate the test number so that the control and fog treatment conditions can be compared.

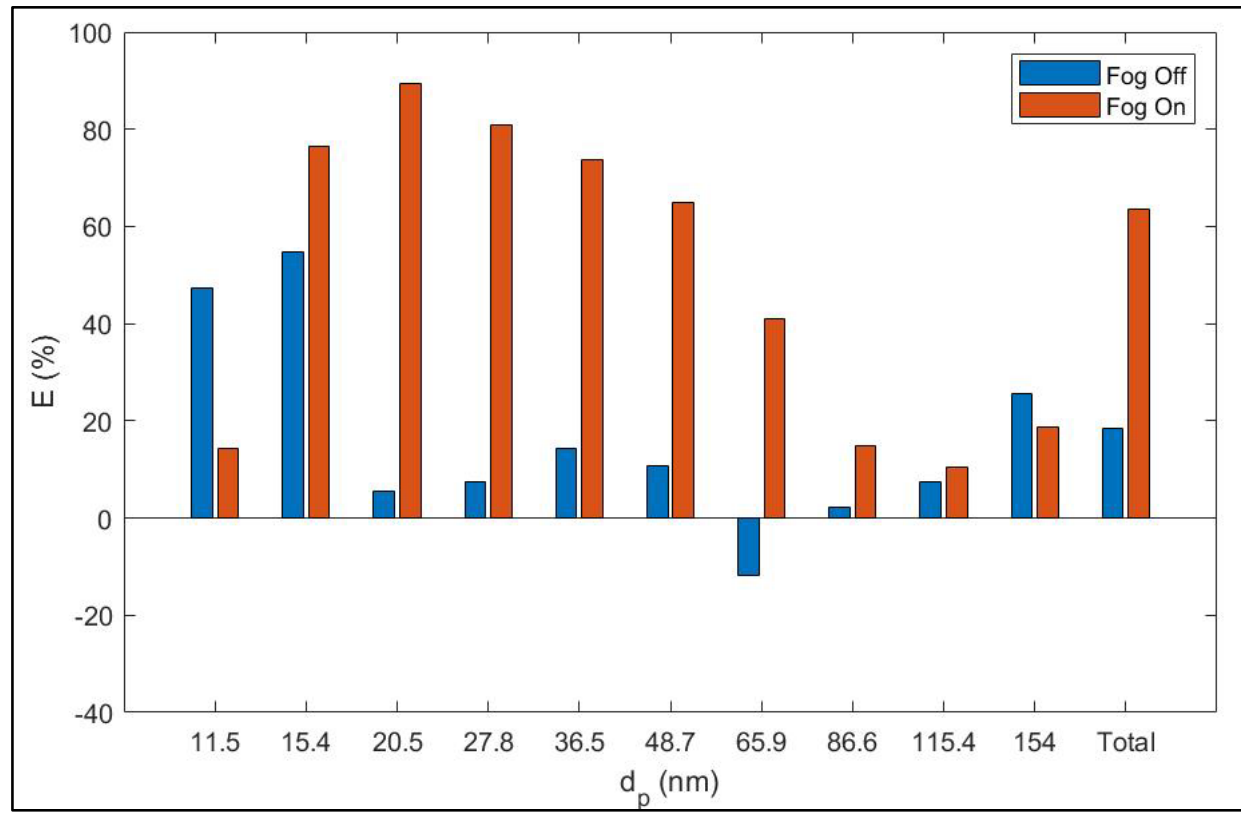

Fig. 4. $E$ for the fog-and-tube scrubber for each size bin. These results were obtained by averaging results across all tests (except Test 9). $E$ for total particles $(11.5-154 \mathrm{~nm}$ ) is also shown to the far right for comparison. 
particles and/or with each other) and to diffusion of these small particles to the tube walls. Particles combining with each other is also likely the cause of the small and negative scavenging coefficients observed in the control condition for intermediate particle diameters (e.g., $65.9 \mathrm{~nm}$ and $86.6 \mathrm{~nm}$ ). Here it may be the case that smaller particles combine to create larger particles, resulting in more particles at the exit than the inlet for these intermediate diameters. Of course, the most striking result shown in Fig. 4 is the significant enhancement of particle removal with the fog treatment for all bins.

\section{DISCUSSION}

The results presented above indicate that significant removal of nanoscale particles from engine exhaust (i.e., DPM) can be achieved via the simple addition of micron-scale fog near the inlet of a long tube. However, the responsible mechanisms are not directly revealed by the data. To gain further insights into the particle removal process, a model was built to enable computational simulations.

\subsection{Model Development}

The particle removal mechanisms included in the simulations were (1) gravitational settling, (2) deposition on the tube wall via turbulent diffusion, and (3) particle-fog drop coagulation followed by drop removal. Drop removal processes included in the simulations (before or after combination with a particle or particles) include (1) gravitational settling and (2) turbulent diffusion of drops to the wall. It is noted that other removal mechanisms were initially considered, including drop evaporation, particle-particle coagulation and drop-drop coagulation. However, preliminary simulations showed that these are insignificant compared to the other mechanisms; though, as noted above, particle-particle interactions may have played a role in the redistribution of particles among size bins, especially for the fog-off condition.

The equations for each of the simulated mechanisms are presented below. These were integrated forward in time for the scrubber inlet conditions in each of the field tests (i.e., inlet measured particle number concentration and size distribution, and computed fog drop number concentration and mean size). The equations were integrated to $t_{R}=60.5 \mathrm{~s}$ (i.e., the scrubber residence time) using a time step of $\Delta t=5 \mathrm{~ms}$, and the resulting particle concentrations in each bin were compared with the actual measurements at the scrubber outlet. A single fitting parameter exists in the equations (described below) and this was adjusted to force the simulations to agree with the experimental results, the significance of which is discussed later.

To compute particle-drop combinations via thermal coagulation, the treatment of Pruppacher and Klett (1978) was followed for particles in each size bin:

$\phi=1-e^{-\Lambda_{c} t}$

where $\phi$ is the fraction of particles that combine with a drop in time $t$ (which is the integration time step $\Delta t$ in the simulations), and $\Lambda_{c}$ is the fractional particle removal rate (in $\mathrm{s}^{-1}$ ):

$$
\Lambda_{c}=2 \pi D_{p} \int_{0}^{\infty} d_{d} N\left(d_{d}\right) d\left(d_{d}\right)
$$

where $d_{d}$ is the diameter of the drops, $N\left(d_{d}\right)$ is the drop size distribution (shown in Fig. S1), $D_{p}$ is the diffusion coefficient for each particle diameter considered here (i.e., the 10 nominal bin sizes between $11.5 \mathrm{~nm}$ and $154 \mathrm{~nm}$ ):

$D_{p}=\frac{k_{c} T F}{3 \pi \mu_{a} d_{p}}$

where $k_{c}$ is the Boltzmann constant, $T$ is temperature (taken as $288 \mathrm{~K}$ ), $d_{p}$ is the particle diameter, and $F$ is the Cunningham correction factor: 
$F=1+\left(\frac{\lambda}{d_{p}}\right)\left(2.34+1.05 \exp \left(-0.39 \frac{d_{p}}{\lambda}\right)\right)$

where $\lambda$ is the mean free path of air (taken as $0.068 \mu \mathrm{m}$ ).

Removal of particles and drops by gravitational settling was obtained following the treatment in Merrell and Saylor (2017) for a circular tube:

$G=\left(1-\frac{\left(\frac{d_{t}^{2}}{2}\right) \operatorname{acos}\left(\frac{l}{d_{t}}\right)-\left(\frac{l}{2}\right) \sqrt{\left(d_{t}^{2}-l^{2}\right)}}{\pi\left(\frac{d_{t}}{2}\right)^{2}}\right)$

where $G$ is the fraction of drops or particles that settle out in time $t, d_{t}$ is the tube diameter, and $I$ is the vertical distance that the drops or particles fall:

$I=t V_{s}$

where $V_{s}$ is the Stokes settling velocity of the drop or particle computed by:

$V_{s}=\frac{\rho d^{2} g}{18 \mu_{a}}$

where $g$ is the gravitational acceleration $\left(9.81 \mathrm{~m} \mathrm{~s}^{-2}\right), d$ is the diameter of the drop or particle, and $\rho$ is the density of the drop (taken as $997 \mathrm{~kg} \mathrm{~m}^{-3}$ ) or the particle (taken as $1225 \mathrm{~kg} \mathrm{~m}^{-3}$, per Virtanen, 2002). Note that after particles are removed by gravitational settling (or any of the other mechanisms considered), it is assumed that at the next time step, the remaining particles are redistributed uniformly within the scrubber tube. In other words, a well-stirred condition is assumed at each time step. The same is true for removal of drops.

Finally, turbulent diffusion of both drops and particles to the tube wall are modeled following the treatment of Hinds (1999):

$W=1-e^{-\frac{\left(4 v_{\text {dep }} t\right)}{d_{t}}}$

where $W$ is the fraction of drops or particles that impact the wall in time $t$, and $V_{\text {dep }}$ is the deposition velocity $\left(\mathrm{m} \mathrm{s}^{-1}\right)$. For each particle diameter being considered, it is assumed that inertial effects are negligible and $V_{\text {dep }}$ is determined by:

$V_{\text {dep } \_p}=\frac{0.04 V}{\operatorname{Re}^{\frac{1}{4}}}\left(\frac{\rho_{g} D_{p}}{\mu a}\right)^{\frac{2}{3}}$

where $V$ is the average tube velocity.

For drops, only inertial effects are considered and are computed according to the treatment of Friedlander and Johnstone (1957):

$V_{\text {dep_d }}=R_{V} \frac{V(f / 2)}{1+\sqrt{f / 2}\left(\frac{1525}{S^{+2}}-50.6\right)}$

where $R_{V}$ is an enhancement factor (fitted as explained below), $f$ is the dimensionless friction factor, 


$$
f=\frac{0.08}{\operatorname{Re}^{\frac{1}{4}}}
$$

and $S^{+}$is the dimensionless stopping distance of drops as they approach the boundary layer at the tube wall,

$$
S^{+}=\frac{0.9 m \rho_{a} V^{2} f / 2}{3 \pi \mu a^{2} d_{d}}
$$

where $m$ is the mass of the spherical drop $\left(d_{d}=4.8 \mu \mathrm{m}, \rho_{d}=997 \mathrm{~kg} \mathrm{~m}^{-3}\right)$ and $\rho_{a}$ and $\mu_{a}$ are the density and viscosity of air as defined above.

It is noted that the enhancement factor $R_{v}$ was not included in the work of Friedlander and Johnstone (1957). Here, it was initially set to 1.0 , and Eqs. (5)-(16) were used to simulate particle and fog drop removal for the scrubber inlet conditions of all field tests. Fig. 5 shows the results for Test 1 in terms of the particle concentration at the scrubber outlet for all size bins. With $R_{V}=$ 1.0 , it is clear that the simulated results substantially underpredict the experimental results-and this was the case for all of the field tests.

To force the simulated concentrations at the scrubber outlet to agree with the experimental observations, $R_{v}$ is hereafter treated as a fitting parameter. This is necessary because, while the equations used in the scrubber simulations for coagulation and settling are obtained from basic physics without empirical assumptions, Eqs. (13)-(16) invoke several key assumptions regarding depositional removal of the particles and drops. Importantly, for deposition of the drops to the tube wall due to inertia, Friedlander and Johnstone (1957) consider the existence of a laminar sublayer which, for the conditions of the experiments conducted here, would be on the order of $2 \mathrm{~mm}$. The presence and collection of water drops in various locations along the tube wall would easily be of this size or larger and would serve to disturb any such sublayer. Similarly the Mylar tubing used in the experimental apparatus had a ribbed structure created by a helical support wire (see Fig. S2) that would also disturb the laminar sublayer. Both effects would cause drop removal to exceed that predicted by Eqs. (14)-(16). Furthermore, while Eqs. (13) and (14) are for

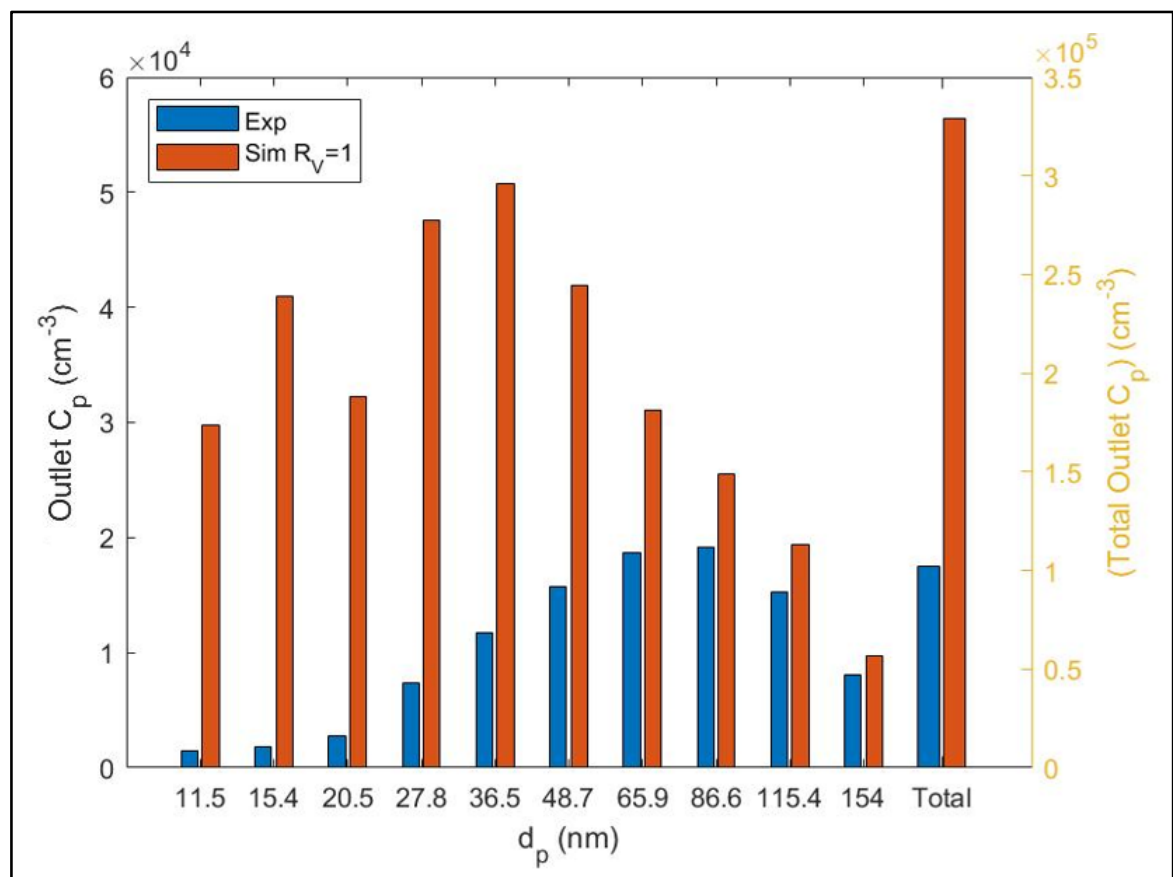

Fig. 5. Particle concentration at the scrubber outlet in each size bin; results are also shown for total particles (11.5-154 $\mathrm{nm}$ ) to the far right. Experimental results are shown from Test 1, and simulated results are shown for the inlet conditions in Test 1 with $R_{v}=1$. 
conditions with a smooth-walled tube, the literature on $V_{\text {dep }}$ in systems with rough, ribbed or wavy walls suggests that these structures will increase predicted deposition by many orders of magnitude (e.g., see El-Shobokshy and Ismail, 1979; Chamberlain et al., 1984; Lai et al., 1999; Sippola and Nazaroff, 2010; Lu and Lu, 2015, 2016; Lu and Wang, 2019; Gradziel and Majewski, 2019; Hayati et al., 2019). However, a review of that literature turned up no studies with parameters directly comparable to those of the current work. Thus, the enhancement factor $R_{V}$ was added for $V_{\text {dep_d }}$ and used as a fitting parameter. (It is noted that no such parameter was used for $V_{\text {dep }} p$ since the experimental results and expected coagulation particle-drop coagulation kinetics indicate that particle removal in the scrubber is primarily due to the fog drops when they are present. That is, diffusion of uncoagulated particles to the tube walls is not expected to be responsible for significant particle removal in the presence of fog.)

\subsection{Simulation Results}

Fig. 6 shows the simulated total particle concentration at the scrubber outlet as a function of $R_{v}$ for the inlet conditions in Test 1 . The (average) experimental particle concentration at the outlet is also shown. There are two aspects of this plot that require discussion: The first concerns the fact that there are two values of $R_{v}$ which force the simulated result to agree with the experimental observations, and the second is the overall magnitude of $R_{v}$ which is necessary to cause this agreement. Each of these interesting observations are examined in turn.

The minimum in Fig. 6 causes there to be two values of $R_{V}$ (and thus $V_{\text {dep }} d$ ) for which the simulated and experimental results agree; these are termed the "lower" and "higher fitted" values and are presented in Table S3 for simulations using inlet conditions for all of the field tests. The existence of a minimum can be understood by recognizing that increasing $R_{V}$ (and thereby $V_{\text {dep_d }}$ ) increases the rate at which drops are removed from the scrubber flow, regardless of whether those drops have combined with a particle or not. At very low values of $R v$, while nearly

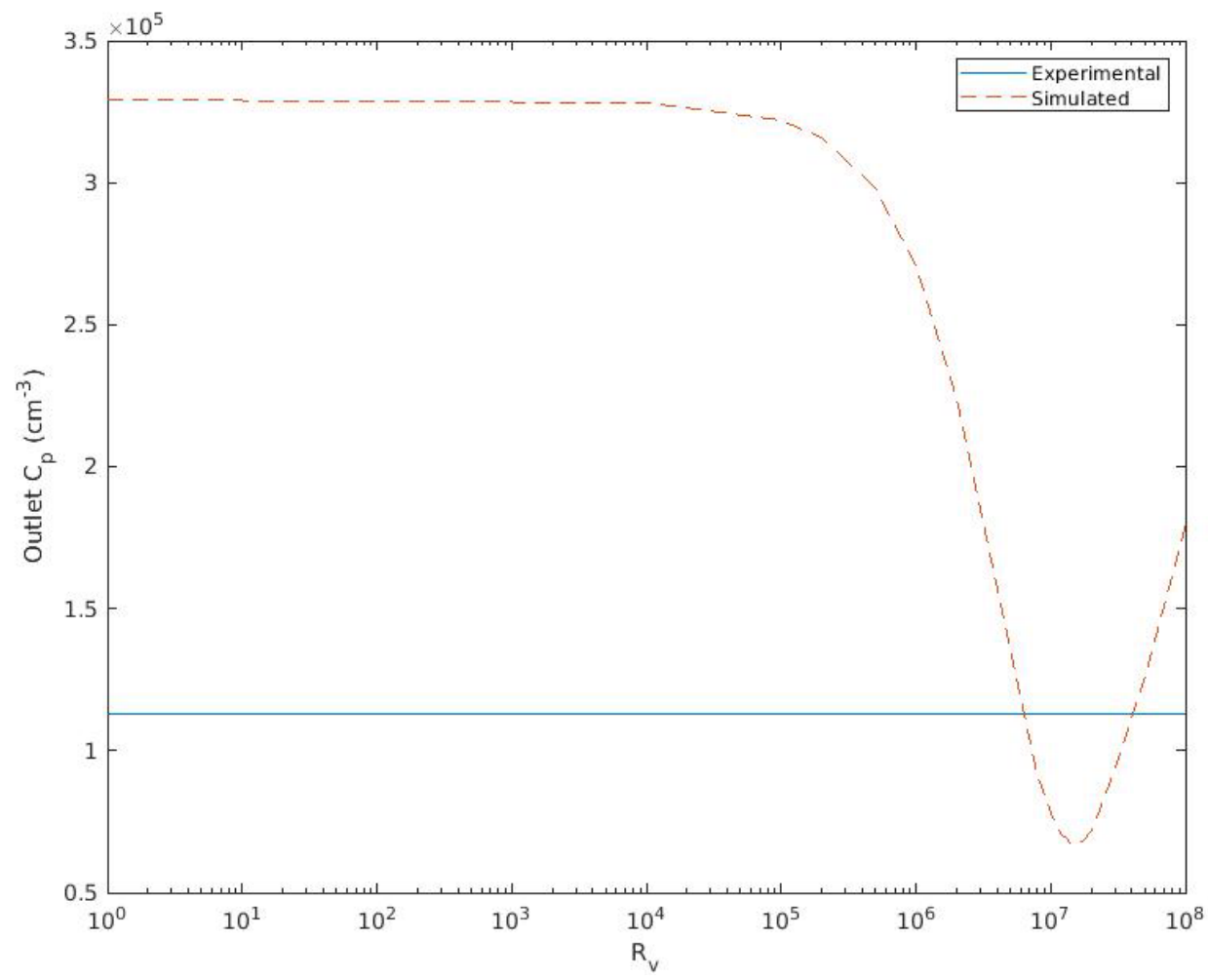

Fig. 6. Simulated particle concentration at the scrubber outlet as a function of $R_{V}$. Results were computed using the inlet conditions from Test 1 and varying $R v$ from $1.0-10^{8}$. The measured outlet concentration $\left(1.13 \times 10^{5} \mathrm{~cm}^{-3}\right)$ in Test 1 is also shown. The simulated results match the experimental results when $R_{V}=6.1 \times 10^{6}$ (at lower fitted $V_{\text {dep }} d=0.21 \mathrm{~cm} \mathrm{~s}^{-1}$ ) and when $R_{V}=4.2$ $\times 10^{8}$ (at higher fitted $V_{\text {dep_d }}=1.4 \mathrm{~cm} \mathrm{~s}^{-1}$ ). 
all particles may have coagulated with fog drops, relatively few of those drops are being removed from the air due to impaction (or settling) such that the particles remain suspended in the airflow (albeit inside drops). At very high values of $R v$, the fog drops are rapidly removed by impaction with the tube walls, so much so that the particles do not have time to coagulate with them, and again the particles remain suspended in the airflow. Hence, there exists an optimum $R_{V}$ for which many particles have combined with drops, and many drops have been removed from the flow.

To understand why very large values of $R_{V}$ are required for the simulations to agree with the experimental observations, it is necessary to revisit the assumptions of Friedlander and Johnston (1957) and compare them with the conditions of the current work. Here, the scrubber tube walls are far from smooth because of the helical raised structure described earlier, and also because deposition of water on the walls results in formation of drops and increasingly rivulets having a range of size, and which effectively serve as roughness elements. Friedlander and Johnston (1957) assumed that drops or particles in a flow would strike the wall due solely to inertia originating in the turbulent fluctuations of the flow. But here, several other inertial effects will surely be present. These include the change in direction of the flow over the ribbed tube wall, change in direction of the flow over water deposited on the tube wall, and the centrifugal effect of any helical flow caused by the helical ribs of the tube. Moreover, the Mylar tubing material was observed to "flutter" in some locations as air flowed through the scrubber during testing, likely enhancing drop deposition even further.

While both the lower and higher fitted $R_{V}$ values yield agreement between the simulated and experimental results for each test, it is unlikely that the higher fitted value corresponds to the experimental conditions. This is because at the higher fitted $R v$ the simulations indicate that virtually all fog drops have impacted the tube walls such that no fog should be present at the outlet, a situation in contradiction with visual observations of fog at the scrubber outlet during the field testing. Hence, the lower fitted value appears more plausible.

Using the lower fitted $R_{v}$ for the scrubber inlet conditions in Test 1, Fig. 7 presents the fraction of particles removed or affected by each of the simulated mechanisms, broken down by size bin. The figure shows that removal of particles in the fog-and-tube scrubber is almost entirely dominated by the removal of DPM-laden drops - meaning that, in the presence of fog, there is negligible removal of free (uncoagulated) particles due to gravitational settling or diffusion to the tube walls.

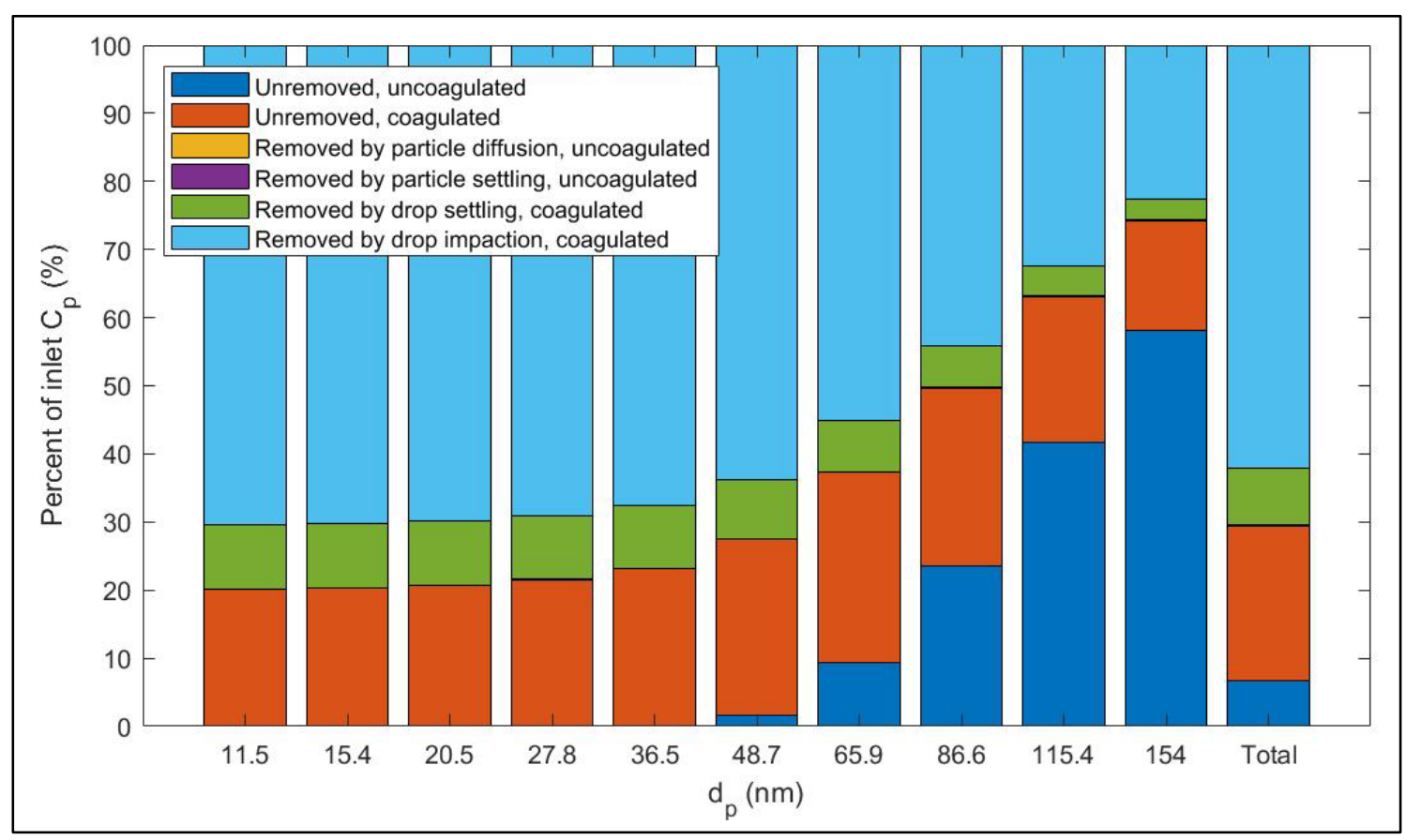

Fig. 7. Simulated fractionation of particles using the scrubber inlet conditions for Test 1 and the lower fitted $R_{V}$ value shown in Fig. 6. If all particles enter the scrubber as unremoved and uncoagulated with drops, the results here indicate the percentage of particles in each possible category at the outlet. Results are shown by size bin and for total particles (11.5-154 nm). 
Moreover, the drop removal is primarily via inertial impaction to the tube walls rather than by settling. This is in contrast to the settling-dominated drop removal proposed by Rojas-Mendoza et al. (2017a), but the bench-scale scrubber apparatus and conditions tested in that work was substantially different than those tested here. For example, the prior work used a rigid, smoothwalled acrylic tube with a much lower flow velocity. Finally, Fig. 7 shows that the number of unremoved particles increases with $d_{p}$, agreeing with the experimental data shown Fig. 4. (Simulated $E$ values for each size bin are shown for all tests in Table S4 and follow generally similar trends.)

The total $E$ was quite high (up to $82 \%$ ) in several of the field tests with application of the fog treatment. As illustrated by Figs. 6 and 7, the simulations suggest that the scrubber could remove even more particles given that the value of $R_{v}$ for the experiments presented here is not the optimal value (i.e., at the minimum in Fig. 6), where maximal particle removal is expected to occur. This is an interesting result in and of itself and is an inherent characteristic of the fog-andtube scrubber, wherein a two-step process for particle removal is dominant: The first step requires that particles coagulate with drops, and the second step requires that these drops are removed (primarily due to impaction). While the first step benefits from a lower airflow velocity or higher retention time, the second step benefits from a higher velocity or other enhancements to the depositional velocity of drops. Research designed to determine regions of the relevant parameter space where the minima is achieved is expected to be fruitful.

\section{CONCLUSIONS}

Exposure to high DPM concentrations represents a serious health hazard. Previous research has suggested that it might be possible to remove nanoscale DPM directly from engine exhaust by application of micron scale fog drops. The current study field tested a fog-and-tube scrubber and demonstrated significant particle removal efficiency (11.5 nm-154 nm), which was highest for the finest particles. These findings are important given that such particles may be especially concerning with respect to health effects, but not easily captured by standard physical filtration or other available engine aftertreatments.

Simulated results using the scrubber inlet conditions from the field testing reveal the dominant particle removal mechanisms. Specifically, in the presence of a high density of fog drops, particles quickly coagulate with the drops, which are then removed from the air flow. For the tested scrubber, drops are removed primarily by inertial impaction to tube walls (rather than gravitational settling, although this does contribute). The simulated results also indicate that further improvement in particle removal efficiency may be possible by optimizing the depositional velocity of the fog drops. This should be considered in the next design phase of the fog-and-tube scrubber.

\section{ACKNOWLEDGEMENTS}

The authors would like to thank the National Institute of Occupational Safety and Health for funding this work. We are also grateful to our mine partner for providing access and logistical support for field testing. The views expressed here are those of the authors and do not necessarily represent the views of research sponsors or partners.

\section{SUPPLEMENTARY MATERIAL}

Supplementary material for this article can be found in the online version at https://doi. org/10.4209/aaqr.210134

\section{REFERENCES}

Bugarski, A.D., Schnakenberg, G.H., Hummer, J.A., Cauda, E., Janisko, S.J., Patts, L.D. (2009). Effects of diesel exhaust after-treatment devices on concentrations and size distribution of aerosols in underground mine air. Environ. Sci. Technol. 43, 6737-6743. https://doi.org/10.10 21/es9006355 
Bugarski, A.D., Janisko, S.J., Cauda, E.G., Noll, J.D., Mischler, S.E. (2011). Diesel Aerosols and Gases in Underground Mines: Guide to Exposure Assessment and Control. Department of Health and Human Services, Public Health Service, Centers for Disease Control and Prevention, National Institute for Occupational Safety and Health, DHHS (NIOSH) Publication No. 2012-101 (RI 9687), Pittsburgh, PA, USA. http://www.cdc.gov/niosh/mining/UserFiles/works/pdfs/2012101.pdf

Cantrell, B., Watts, W. (1997). Diesel exhaust aerosol: Review of occupational exposure. Appl. Occup. Environ. Hyg. 12, 1019-1027. https://doi.org/10.1080/1047322X.1997.10390643

Chamberlain, A.C., Garland, J.A., Wells, A.C. (1984). Transport of gases and particles to surfaces with widely spaced roughness elements. Boundary Layer Meteorol. 29, 343-360. https://doi.org/ 10.1007/BF00120534

Dementhon, J., Martin, B. (1997). Influence of various diesel traps in particulate size distribution. SAE Technical Paper 972999. https://doi.org/10.4271/972999

Dockery, D.W., Pope, C.A., Xu, X., Spengler, J.D., Ware, J.H., Fay, M.E., Ferris, B.G., Speizer, F.E. (1993). An association between air pollution and mortality in six U. S. cities. N. Engl. J. Med. 329, 1753-1759. https://doi.org/10.1056/NEJM199312093292401

El-Shobokshy, M.S., Ismail, I.A. (1979). Deposition of aerosol particles from turbulent flow onto rough pipe wall. Atmos. Environ. 14, 297-304. https://doi.org/10.1016/0004-6981(80)90063-3

Friedlander S.K., Johnstone, H.F. (1957). Deposition of Suspended particles from turbulent gas streams. Ind. Eng. Chem. 49, 1151-1156. https://doi.org/10.1021/ie50571a039

Gradziel, S., Majewski, K. (2019). Experimental determination of the friction factor in a tube with internal helical ribs. Energies 12, 257-274. https://doi.org/10.3390/en12020257

Hayati, H., Goharrizi, A.S., Salmanzadeh, M., Ahmadi, G. (2019). Numerical modeling of particle motion and deposition in turbulent wavy channel flows. Sci. Iran. 26, 2229-2240. https://doi.org/ 10.24200/SCI.2019.21405

Heyder, J., Gebhart, J., Rudolf, G., Schiller, C.F., Stahlhofen, W. (1986). Deposition of particles in the human respiratory tract in the size range 0.005-15 $\mu \mathrm{m}$. J. Aerosol Sci. 17, 811-825. https://doi.org/10.1016/0021-8502(86)90035-2

Hinds, W.C. (1999). Aerosol Technology: Properties, Behavior, and Measurement of Airborne Particles. 2nd Edition. Wiley-Interscience, New York.

Kittelson, D.B., Watts, W.F., Johnson, J.P., Rowntree, C., Payne, M., Goodier, S., Warrens, C., Preson, H., Zink, U., Ortiz, M., Goersmann, C., Twigg, M.V., Walker, A.P., Caldow, R. (2009). Onroad evaluation of two diesel exhaust aftertreament devices. J. Aerosol Sci. 37, 1140-1151. https://doi.org/10.1016/j.jaerosci.2005.11.003

Kittleson, D. (1998). Engines and nanoparticles: A review. J. Aerosol Sci. 29, 575-588. https://doi.org/10.1016/S0021-8502(97)10037-4

Lai, A.C.K., Bryne, M.A., Goddard, A.J.H. (1999). Measured deposition of aerosol particles on a two-dimensional ribbed surface in a turbulent duct flow. J. Aerosol Sci. 30, 1201-1214. https://doi.org/10.1016/S0021-8502(99)00021-X

Lu, H., Lu, L. (2015). Effects of rib spacing and height on particle deposition in ribbed duct air flows. Build. Environ. 92, 317-327. https://doi.org/10.1016/j.buildenv.2015.04.035

Lu, H., Lu, L. (2016). CFD investigation on particle deposition in aligned and staggered ribbed duct air flows. Build. Environ. 93, 697-706. https://doi.org/10.1177/1420326X16662509

Lu, H., Wang, Y. (2019). Particle deposition in ventilation ducts: A review. Build. Simul. 12, 723734. https://doi.org/10.1007/s12273-019-0522-8

Maricq, M.M., Chase, R.E., Xu, N., Laing, P.M. (2002) The effects of the catalytic converter and fuel sulfur level on motor vehicle particulate matter emissions: Light duty diesel vehicles. Environ. Sci. Technol. 36, 283-289. https://doi.org/10.1021/es010962l

Merrell, T.M., Saylor, J.R. (2017). Demisting using an ultrasonic standing wave field. J. Acoust. Soc. Am. 141, 171-182. https://doi.org/10.1121/1.4973689

Mine Safety and Health Administration (MSHA) (2021). DPM personal sampling compliance data from metal/non-metal mines. https://arlweb.msha.gov/OpenGovernmentData/OGIMSHA.asp (accessed 29 January 2021).

Oberdorster, G., Oberdorster, E., Oberdorster, J. (2005). Nanotoxicology: An emerging discipline evolving from studies of ultrafine particles, Environ. Health Perspect. 113, 823-839. https://doi.org/10.1289/ehp.7339 
Oberdorster, G., Stone, V., Donaldson, K. (2007). Toxicology of nanoparticles: A historical perspective. Nanotoxicology 1, 2-25. https://doi.org/10.1080/17435390701314761

Pope, C.A., Thun, M.J., Namboodiri, M.M., Dockery, D.W., Evans, J.S., Speizer, F.E., Heath, C.W. (1995). Particulate air pollution as a predictor of mortality in a prospective study of U. S. adults. Am. J. Respir. Crit. Care. Med. 151, 669-674. https://doi.org/10.1164/ajrccm/151.3_Pt_1.669

Pruppacher, H., Klett, J. (1978). Microphysics of Clouds and Precipitation. Reidel Publishing Company, Dordrecht.

Ristovski, Z.D., Miljevic, B., Surawksi, N.C., Morawska, L., Fong, K.M., Goh, F., Yang, I.A. (2012). Respiratory health effects of diesel particulate matter. Respirology 17, 201-212. https://doi.org/ 10.1111/j.1440-1843.2011.02109.x

Rojas-Mendoza, L., McCullough, E., Sarver, E., Saylor, J.R. (2015). A preliminary Investigation of DPM Scavenging by Water Sprays. In Proc. $15^{\text {th }}$ North American Mine Ventilation Symposium. pp. 325-330.

Rojas-Mendoza, L., Sarver, E., Saylor, J.R. (2017a). Removal of DPM from an airstream using micron-scale droplets. Aerosol Air Qual. Res. 17, 1865-1874. https://doi.org/10.4209/aaqr.20 17.03.0093

Rojas-Mendoza, L., Sarver, E., Saylor, J.R. (2017b). Laboratory Demonstration of DPM mass removal from an exhaust stream by fog drops. Min. Eng. 69, 55-60. https://doi.org/10.19150/ me.7854

Schnakenberg, G.H., Bugarski, A. (2002). Review of technology available to the underground mining industry for control of diesel emissions. DHHS (NIOSH) Publication No. 2002-154.

Sippola, M.R., Nazaroff, W.W. (2010) Experiments measuring particle deposition from fully developed turbulent flow in ventilation ducts. Aerosol Sci. Technol. 38, 914-925. https://doi.org/10.1080/027868290507213

Sydbom, A., Blomberg, A., Parnia, S., Stenfors, N., Sandström, T., Dahlén, S.E. (2001). Health effects of diesel exhaust emissions. Eur. Respir. J. 17, 733-746. https://doi.org/10.1183/09031 936.01.17407330

Vaaraslahti, K., Virtanen, A., Ristimaki, J., Keskinen, J. (2004). Nucleation mode formation in heavy-duty diesel exhaust with and without a particulate filter. Environ. Sci. Technol. 38, 48844890. https://doi.org/10.1021/es0353255

Virtanen, A., Ristimäki, J., Marjamäki, M., Lehtoranta, K., Keskinen, J., Lappi, M. (2002). Effective density of diesel exhaust particles as a function of size. SAE Technical Paper 2002-01-0056. https://doi.org/10.4271/2002-01-0056

Vogt, R., Scheer, V., Casati, R., Beter, T. (2003). On-road measurement of particle emission $\mathrm{n}$ the exhaust plume of a diesel passenger car. Environ. Sci. Technol. 37, 4070-4076. https://doi.org/ 10.1021/es0300315

Wade, J.F., Newman, L.S. (1993). Diesel asthma: Reactive airways disease following overexposure to locomotive exhaust. J. Occup. Med. 35, 149-154. https://doi.org/10.1097/00043764199302000-00015 